\title{
Fenótipo S1 de Esterase em Meloidogyne incognita no Brasil
}

\author{
Dagoberto S. Oliveira ${ }^{1}$, Rosângela D. L. Oliveira ${ }^{1}$ \& Wallace Gonçalves ${ }^{2}$ \\ ${ }^{1}$ Departamento de Fitopatologia, Universidade Federal de Viçosa, CEP 36570-000, Viçosa, MG, \\ e-mail: dagoberto@vicosa.ufv.br, rdlima@ufv.br; ${ }^{2}$ Instituto Agronômico de Campinas, Cx. Postal 28, \\ CEP 13001-970, Campinas, SP, e-mail: wallace@iac.sp.gov.br
}

(Aceito para publicação em 27/07/2004)

Autor para correspondência: Rosângela D’Arc de Lima Oliveira

\begin{abstract}
Esterase phenotype S1 in Meloidogyne incognita in Brazilian coffee plantations

The rare esterase phenotype S1 of Meloidogyne incognita is reported here for the first time in Brazil. The root-knot nematode studied population was detected in a coffee (Coffea arabica) field in the state of São Paulo. The affected plants had typical symptoms of the $M$. incognita parasitism.
\end{abstract}

Em 2003, no município de Garça SP, amostras de solo e raiz foram coletadas em cafezais que exibiam quadro sintomatológico característico do ataque de Meloidogyne incognita (Kofoid \& White) Chitwood. Fêmeas retiradas das raízes de cada amostra foram submetidas à análise dos fenótipos de esterase em gel de poliacrilamida. Em uma das propriedades foi encontrada uma população de Meloidogyne sp. com perfil de esterase diferente dos já detectados em nematóides das galhas de cafeeiro (Coffea arabica L.). A população apresentou o fenótipo S1 (Figura 1A), que se caracteriza pela presença de uma banda de menor mobilidade em relação àquela primeira banda de $M$. javanica (Treub) Chitwood, utilizada como padrão de comparação, eao fenótipo I1, típico de $M$. incognita. Para dirimir dúvidas referentes ao diagnóstico dessa população atípica foram analisados perfis de outras isoenzimas, configuração da região perineal, estrutura do estilete de fêmeas, características da região labial de machos e teste de hospedeiros diferenciadores da Universidade Estadual da Carolina do Norte. A população apresentou os fenótipos N1, I2 e N1 para as enzimas malato desidrogenase, superóxido dismutase e glutamatooxaloacetato transaminase, respectivamente. As configurações perineais das fêmeas avaliadas apresentaram arco dorsal alto e trapezoidal, estrias onduladas e bifurcações na região dos campos laterais (Figura 1B). O estilete das fêmeas possuía o cone curvo na extremidade, com aumento gradual do diâmetro da haste em direção à base (Figura 1C). Os discos labiais dos machos mostraram-se planos a côncavos. O tomateiro (Lycopersicon esculentum Mill.) 'Rutgers', a melancia (Citrullus vulgaris Schrad.) 'Charleston Gray' e o pimentão (Capsicum annuum L.) 'Early California Wonder' se mostraram hospedeiros da população. A análise conjunta de todas as características confirmou que a população pertencia à espécie $M$. incognita, raça 1 . Este é o primeiro relato do fenótipo $\mathrm{S} 1 \mathrm{em} M$. incognita infectando o cafeeiro no Brasil, fato relevante não só para a diagnose da doença como para os trabalhos de melhoramento visando resistência a esse patógeno.

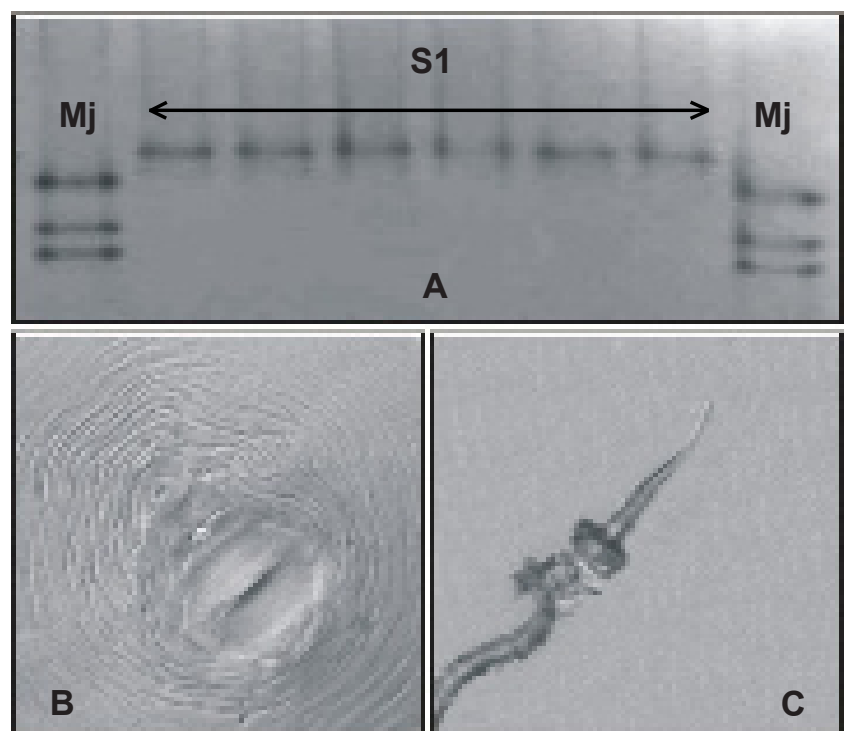

FIG. 1 - Fenótipo isoenzimático e características morfológicas de uma população de Meloidogyne incognita, proveniente de cafeeiro (Coffea arabica): A - fenótipo $\mathrm{S} 1$ de esterase $(\mathrm{Mj}=$ M. javanica, utilizado como padrão de comparação); B - configuração perineal; C - estilete da fêmea. 